\title{
Targeted Screening and Quantification of dl-PCBs and Dioxins in Various Foodstuffs by Programmed-temperature Vaporizer Large-volume Injection Coupled to GC-MS
}

\author{
Ngoc Huy Ho*, Aurélie Bugey, Pierre Zimmerli, Joëlle Nançoz, Didier Ortelli, and Patrick Edder
}

\begin{abstract}
In 2009, high concentrations of polychlorinated dibenzo-p-dioxins (PCDDs), polychlorinated dibenzofurans (PCDFs) and dioxin-like polychlorinated biphenyls (dl-PCBs) were found in soils located near the municipal garbage incinerator of Geneva. The matter of food contamination in this area was raised. Based on exposure criteria, a strategy of analysis of animal fats has been established with farmers in the Geneva area. Most methods of analysis of dl-PCBs, dioxins and furans, are based on gas chromatography coupled to highresolution mass spectrometry (GC-HRMS) and considered as the reference methodology. An innovative approach was developed by programmed-temperature vaporizer large-volume injection (PTV-LV) and gas chromatography coupled with triple quadrupole mass spectrometry (GC-MS/MS) analysis. This analytical method was validated and was found suitable for screening and quantification of target compounds in animal fats (beef, pork, sheep, etc.). PTV-LV coupled to GC-MS/MS appeared to be a good alternative compared to the GC-HRMS strategy, offering a good compromise between sensitivity, versatility of instrumentation, and economical aspects. A survey of 121 samples was conducted.
\end{abstract}

Keywords: Dioxin-like polychlorinated biphenyls · Large volume injection · Polychlorinated dibenzofurans . Polychlorinated dibenzo- $p$-dioxins · Tandem mass spectrometry

\section{Introduction}

The common name 'dioxin' combines a group of compounds such as the polychlorinated dibenzo- $p$-dioxins (PCDDs) and polychlorinated dibenzofurans (PCDFs). These two groups together are commonly named PCDD/Fs. There are 75 and 135 congeners for PCDDs and PCDFs respectively, depending on the number and position of chlorine atoms in the aromatic rings, but only a few of them are considered risky to human health. ${ }^{[1]}$ Some polychlorinated biphenyls (PCBs) have similar toxic effects to highly toxic $2,3,7,8$-tetrachlorodibenzo- $p$-dioxin $\quad(2,3,7,8$-TCDD) and therefore are considered as dioxin-like PCBs (dl-PCBs). All these compounds represent more than 400 individual mol-

\footnotetext{
${ }^{*}$ Correspondence: Dr. N. H. Ho
}

Official Food and Veterinary Control Authority

of Geneva

Quai Ernest-Ansermet 22

$\mathrm{CH}-1205$ Geneva

Tel.: +41225465613

E-mail: ngoc-huy.ho@etat.ge.ch ecules, which have to be separated from each other to ensure distinctive quantification of the target molecules. ${ }^{[2]}$

PCBs were produced on a massive scale and widely used as industrial chemicals, particularly as dielectric fluids in electrical transformers and capacitors, hydraulic fluids, lubricating and cutting oils, as well as additives in sealants, plastics, paints, copying paper, adhesives and casting agents. ${ }^{[3]}$ The production and use of PCBs was completely forbidden in Switzerland in 1986, but these compounds are still present in capacitors of electrical installations and in building materials. Dioxins are characterized by low water solubility and high fat solubility. They are defined as persistent organic chemicals in the environment and are able to bioaccumulate through the food chain in living species, posing a risk for human health. The formation of PCDDs and PCDFs occurs when industrial material is burned at low temperature in presence of chlorine. The incineration of garbage in large quantity produces the majority of contaminant dioxins in the environment. ${ }^{[4]}$ In food control, both dl-PCBs and PCDD/ Fs have to be monitored, because different pathways of contamination are likely to happen and do not present constant concentrations or patterns. ${ }^{[5]}$
The activity of the municipal garbage incinerator Les Cheneviers in Geneva, Switzerland, was the main source of dioxins in the atmosphere in this area, but since the 1970s, emissions have been reduced by the installation of efficient electro filters, washers and catalysts. ${ }^{[6]}$ At the present time, the emissions of dioxins are compliant with standards set in Switzerland in 2006. [7]

29 congeners (7 PCDDs, 10 PCDFs and 12 dl-PCBs) among these three classes of cyclic aromatic chlorinated compounds, have a molecular shape close to the highly toxic 2,3,7,8-TCDD. ${ }^{[8]}$ Since the individual toxicity of each compound is different, Commission Regulation (EC) No 1881/2006 lays down the use of toxic equivalent factors (TEF) to facilitate risk assessment and regulatory control. ${ }^{[9]}$ The analytical results of all individual dioxin and dioxin-like PCB congeners is expressed in terms of 2,3,7,8-TCDD toxic equivalents $\left(\mathrm{TEQ}_{98}\right)$ using the TEF estimated by the World Health Organization (WHO) in 1998 (Table 1). ${ }^{[10]}$ The limits allowed in foodstuffs are published by the WHO and local authorities. Examples of European Community Maximum Residue Level (MRL) are given in Table 2. 
In 2004, 58 samples of soil were analyzed by the Geneva Industrial Services (SIG) to determine the content in dioxins within a radius of $5 \mathrm{~km}$ from the incinerator. ${ }^{[11]}$ The concentrations in dioxins of nine samples collected within $1 \mathrm{~km}$ from the epicenter, were higher than the regulation of $20 \mathrm{ng}$ TEQ/kg. ${ }^{[12]}$ Following these results, research was undertaken to evaluate the potential correlation between the distance to the incinerator and the occurrence of cancer in Les Cheneviers area. The Genevan tumor registry excluded a connection between the two events.[13]

The use of selective and sensitive analytical methods is required for the suitable determination of these compounds in samples. Due to the high lipophilicity of the compounds, the analysis requires many purification steps. The procedure generally consists of sample extraction, adsorption chromatography columns clean-ups prior to the injection into gas chromatography coupled to high-resolution mass spectrometry (GC-HRMS). [14]

As described in US EPA Method 1668, GC-HRMS is the reference method which should be used for the quantification of samples with a significant level of dioxin. [15] But the use of this technique requires qualified people as well as cost-effective instruments. Therefore GC coupled with triple quadrupole mass spectrometry (GC-MS/ MS) has been used to analyze dioxins and furans. ${ }^{[16]}$ The detection afforded by MS/ MS instruments has equivalent selectivity but is less sensitive than HRMS. Its performance can be increased by optimization of sample cleaning steps, adjustment of sample size and use of an alternative injection technique such as large-volume injection. Tandem mass spectrometry can thus be a good alternative method of screening prior to confirmatory analysis by HRMS and can reduce the laboratory workload by highlighting samples that are either nondetected, or which have extremely high levels of concentrations. ${ }^{[17]}$ The approach is relevant because more than $95 \%$ of the samples randomly controlled, are generally compliant with regulatory limits. ${ }^{[18]}$

\section{Materials and Methods}

\subsection{Chemicals and Reagents}

Acetone, cyclohexane and ethyl acetate of Pesti-S grade reagents were provided by Biosolve (Dieuze, France), whereas n-hexane Pestinorm was obtained from VWR (Dietikon, Switzerland). Dichloromethane, methanol Lichrosolv and anhydrous sodium sulfate were purchased from Merck (Darmstadt, Germany). Sulfuric acid (95$97 \%)$ and potassium hydroxide $(\geq 86 \%)$ were obtained from Sigma-Aldrich (Buchs, Switzerland).

Table 1. Toxic equivalent factors (TEFs) for dioxins and related compounds

\begin{tabular}{|c|c|c|c|}
\hline & Compound & Congener & $\begin{array}{l}\text { WHO- } \\
\text { TEF }_{98}\end{array}$ \\
\hline \multirow[t]{7}{*}{ dibenzo- $p$-dioxins } & DD048 & 2,3,7,8-TeCDD & 1 \\
\hline & DD054 & $1,2,3,7,8-\mathrm{PeCDD}$ & 1 \\
\hline & DD066 & $1,2,3,4,7,8-\mathrm{HxCDD}$ & 0.1 \\
\hline & DD067 & $1,2,3,6,7,8-\mathrm{HxCDD}$ & 0.1 \\
\hline & DD070 & $1,2,3,7,8,9-\mathrm{HxCDD}$ & 0.1 \\
\hline & DD073 & 1,2,3,4,6,7,8-HpCDD & 0.01 \\
\hline & DD075 & OCDD & 0.0001 \\
\hline \multirow[t]{10}{*}{ dibenzofurans } & DF083 & $2,3,7,8-\mathrm{TeCDF}$ & 0.1 \\
\hline & DF094 & $1,2,3,7,8-\mathrm{PeCDF}$ & 0.05 \\
\hline & DF114 & 2,3,4,7,8-PeCDF & 0.5 \\
\hline & DF118 & $1,2,3,4,7,8-\mathrm{HxCDF}$ & 0.1 \\
\hline & DF121 & $1,2,3,6,7,8-\mathrm{HxCDF}$ & 0.1 \\
\hline & DF130 & $2,3,4,6,7,8-\mathrm{HxCDF}$ & 0.1 \\
\hline & DF124 & $1,2,3,7,8,9-\mathrm{HxCDF}$ & 0.1 \\
\hline & DF131 & $1,2,3,4,6,7,8-\mathrm{HpCDF}$ & 0.01 \\
\hline & DF134 & $1,2,3,4,7,8,9-\mathrm{HpCDF}$ & 0.01 \\
\hline & DF135 & OCDF & 0.0001 \\
\hline \multirow{4}{*}{$\begin{array}{l}\text { non-ortho } \\
\text { polychlorobiphenyls }\end{array}$} & PCB 77 & 3,3',4,4'-Tetrachlorobiphenyl & 0.0001 \\
\hline & PCB 81 & 3,4,4',5-Tetrachlorobiphenyl & 0.0001 \\
\hline & PCB 126 & 3,3',4,4',5-Pentachlorobiphenyl & 0.1 \\
\hline & PCB 169 & 3,3',4,4',5,5'-Hexachlorobiphenyl & 0.01 \\
\hline \multirow{8}{*}{$\begin{array}{l}\text { Mono-ortho } \\
\text { polychlorobiphenyls }\end{array}$} & PCB 105 & 2,3,3',4,4'-Pentachlorobiphenyl & 0.0001 \\
\hline & PCB 114 & 2,3,4,4',5-Pentachlorobiphenyl & 0.0005 \\
\hline & PCB 118 & 2,3',4,4',5-Pentachlorobiphenyl & 0.0001 \\
\hline & PCB 123 & 2',3,4,4',5-Pentachlorobiphenyl & 0.0001 \\
\hline & PCB 156 & 2,3,3',4,4',5-Hexachlorobiphenyl & 0.0005 \\
\hline & PCB 157 & 2,3,3',4,4',5'-Hexachlorobiphenyl & 0.0005 \\
\hline & PCB 167 & 2,3',4,4',5,5'-Hexachlorobiphenyl & 0.00001 \\
\hline & PCB 189 & 2,3,3',4,4',5,5'-Heptachlorobiphenyl & 0.0001 \\
\hline
\end{tabular}

Table 2. Maximum levels in foodstuffs

Foodstuffs

Hen eggs and egg products

Fat of the following animals:

- bovine animals and sheep - pigs

Biobeads S-X3, 200-400 mesh was supplied by Bio-Rad (Hercules, USA) and florisil absorbent for chromatography was obtained from Riedel-de-Haën (Buchs, Switzerland). Water was purified with a Milli-Q system from Millipore (Molseheim, France).

The following analytes were determined:

\section{Maximum levels}

\begin{tabular}{c|c}
$\begin{array}{c}\text { Sum of dioxins } \\
\text { (WHO-PCDD/Fs- } \\
\text { TEQ }_{98} \text { ) }\end{array}$ & $\begin{array}{c}\text { Sum of dioxins and dioxin-like } \\
\text { PCBs (WHO-PCDD/Fs-dl- } \\
\text { PCBs-TEQ }\end{array}$ ) \\
\hline $3.0 \mathrm{pg} / \mathrm{g}$ fat & $6.0 \mathrm{pg} / \mathrm{g}$ fat \\
& \\
$3.0 \mathrm{pg} / \mathrm{g}$ fat & $4.5 \mathrm{pg} / \mathrm{g}$ fat \\
$1.0 \mathrm{pg} / \mathrm{g}$ fat & $1.5 \mathrm{pg} / \mathrm{g}$ fat
\end{tabular}

i) Native PCB standards $77,81,105$, $114,118,123,126,156,157,167,169$ and 189.

ii) ${ }^{13} \mathrm{C}_{12}$-labelled PCB standards 77, 81, $105,114,118,123,126,156,157,167,169$ and 189.

iii) Native PCDD standards 48, 54, 66, 67, 70, 73, 75 and PCDF standards 83, 94, $114,118,121,130,124,131,134$ and 135. 
iv) ${ }^{13} \mathrm{C}_{12}$-labelled PCDD 48, 54, 6773 and 75 and ${ }^{13} \mathrm{C}_{12}$-labelled PCDF 83, 94, $118,131,135$.

These standards were obtained either from Cambridge Isotope Laboratories (Andover, USA) or Dr Ehrenstorfer (Augsburg, Germany). All analytical standards, native as well as ${ }^{13}$ carbon labelled, were prepared by dissolving an appropriate amount of each reference substance in methanol.

\subsection{Sample Preparation}

\subsubsection{Extraction}

The sample preparation was based on the official method 1613 Environmental Protection Agency.[19] Samples were first homogenized using a Büchi B-400 mixer (Büchi Labortechnik, Flawil, Switzerland). $20 \mathrm{~g}$ of sample (25 $\mathrm{g}$ for egg yolk) were dissolved in $100 \mathrm{~mL}$ solution of hexane-acetone (50:50, v/v). The mixture was dispersed with Polytron PT 10-35 GT (Kinematica, Littau, Switzerland) for $5 \mathrm{~min}$ and then centrifuged by Heareus Varifuge 3.0 (DJB Labcare, Buckinghamshire, England) for $5 \mathrm{~min}$ at $3000 \mathrm{rpm}$.

The supernatant was transferred in a $250 \mathrm{~mL}$ Büchi Vessel with $1 \mathrm{~mL}$ residual appendix. Acetone was evaporated with a Büchi Syncore Analyst R6 (Büchi Labortechnik, Flawil, Switzerland) then hexane was added to obtain a final volume of $250 \mathrm{~mL}$. The extraction solvent was spiked with $40 \mu \mathrm{L}$ of internal standards at the following concentrations : ${ }^{13} \mathrm{C}_{12}$-PCB $77,81,126,169$ at $20 \mu \mathrm{g} / \mathrm{L} ;{ }^{13} \mathrm{C}_{12}^{12}-\mathrm{PCB}$ $105,114,118,123,156,157,167$ and 189 at $10 \mu \mathrm{g} / \mathrm{L} ;{ }^{13} \mathrm{C}_{12}$-PCDD54, DF94, DF118, DD48, DF83 and DD67 at $10 \mu \mathrm{g} / \mathrm{L} ;{ }^{13} \mathrm{C}_{12}{ }^{-}$ PCDD73, DD75, DF131 and DF135 at 20 $\mu \mathrm{g} / \mathrm{L}$. The sample was treated twice with $20 \mathrm{~mL}$ of sulfuric acid to isolate the organic phase containing the PCDD/Fs and dlPCBs. The n-hexane fractions were concentrated to $4.5 \mathrm{~mL}$ by the Syncore system before the clean-up process.

\subsubsection{Clean-up}

GPC purification was carried out twice on a Gilson GX-271 sampler (Gilson, Middleton, US) with an Omnifit column $500 \times 25 \mathrm{~mm}$ i.d. (Bio Chem Fluidics, Boonton, USA) connected to a Gilson 307 pump. The column was packed with $70 \mathrm{~g}$ of S-X3 Bio-Rad using a mixture ethyl acetate-cyclohexane $(50: 50, \mathrm{v} / \mathrm{v})$ as solvent. Bio-Beads were conditioned overnight in solvent at $5 \mathrm{~mL} / \mathrm{min}$ by closed-loop at room temperature before packing. The lifetime was estimated after examination of the chromatograms.

The dissolved sample was loaded on the column and the elution was performed at $5 \mathrm{~mL} / \mathrm{min}$ rate. The fraction correspond- ing to the first 34 min of elution was discarded to waste. The fraction containing the analytes was eluted between 34 and 52 min and the resulting $90 \mathrm{~mL}$ were collected and reduced to $1 \mathrm{~mL}$ before the remaining clean-up steps.

An additional clean-up was performed using the Florisil phase. The powder was previously activated in an oven heated at $620^{\circ} \mathrm{C}$ for 12 hours, and cooled in a desiccator at room temperature. Water was added to a concentration of $4 \%$ in the powder and it was kept in a hermetic glass bottle. Cotton wool was placed in a glass chromatographic column before adding $5 \mathrm{~g}$ of florisil. A pre-elution was operated with 10 $\mathrm{mL}$ of dichloromethane and with $10 \mathrm{~mL}$ n-hexane-dichloromethane solution (98:2, $\mathrm{v} / \mathrm{v})$. The extract was loaded on the column and the PCDD/Fs as well as dl-PCBs were eluted using successively $20 \mathrm{~mL}$ of n-hexane-dichloromethane $(98: 2, \mathrm{v} / \mathrm{v})$ and $35 \mathrm{~mL}$ of dichloromethane.

The eluate was concentrated to $1 \mathrm{~mL}$ by the Syncore system and reduced to a final volume of $40 \mu \mathrm{L}$ by Dri-Block DB3 (Techne, Stone, UK) sample concentrator.

\subsection{GC-MS/MS Apparatus}

The GC-MS/MS experiments were carried out on Agilent Series 7890 apparatus (Agilent Technologies, Palo Alto, USA) coupled to a Quattro Micro Micromass (Waters, Manchester, UK) equipped with a Combi Pal autosampler (CTC Analytics, Zwingen, Switzerland).

The column set consisted of a $30 \mathrm{~m}$ $\times 0.25 \mathrm{~mm}$ i.d., $0.25 \mu \mathrm{m}$ film thickness DB-5MS (5\% phenyl-95\% methylpolysiloxane) from Agilent Technologies (BGB Analytik, Boeckten, Switzerland). Temperature program operation was used with an initial oven temperature of $80{ }^{\circ} \mathrm{C}$ held for $2 \mathrm{~min}$, ramped at $30^{\circ} \mathrm{C} / \mathrm{min}$ to 170 ${ }^{\circ} \mathrm{C}$, then increased at $5{ }^{\circ} \mathrm{C} / \mathrm{min}$ to $320{ }^{\circ} \mathrm{C}$ and finally held at final temperature for 15 min. Pure GC grade helium was used as carrier gas at a constant flow of $1.5 \mathrm{~mL} /$ $\min$.

PTV injections can be divided into four steps: injection, solvent evaporation, analyte transfer and cleaning. For the injection step, the split valve was opened and $20 \mu \mathrm{L}$ samples were injected into a multi baffle deactivated $1.8 \mathrm{~mm}$ i.d. liner (BGB Analytik, Boeckten, Switzerland) at $20{ }^{\circ} \mathrm{C}$ by cooling the injector with $\mathrm{CO}_{2}$. The solvent was evaporated with a vent flow of 40 $\mathrm{mL} / \mathrm{min}$ for $1 \mathrm{~min}$. During the transfer step, the split valve was closed and the temperature was raised to $280{ }^{\circ} \mathrm{C}$ at a rate of 720 ${ }^{\circ} \mathrm{C} / \mathrm{min}$ in splitless mode. Finally the temperature was increased to $320^{\circ} \mathrm{C}$ at a rate of $720^{\circ} \mathrm{C} / \mathrm{min}$ and held for $5 \mathrm{~min}$ with a purge flow of $50 \mathrm{ml} / \mathrm{min}$ for cleaning.

Identification and quantitation were done in electronic ionization mode (EI+) in Multiple Reaction Monitoring mode (MRM) using the pseudomolecular ion as precursor and $[\mathrm{M}-2 \mathrm{Cl}]^{+}$for dl-PCBs, as well as $[\mathrm{M}-\mathrm{COCl}]^{+}$for $\mathrm{PCDD} / \mathrm{Fs}$, as product ions. A second MRM transition was used to fulfill the common criteria of selectivity (Table 3 ).

Temperatures of ion source and transfer line were respectively 200 and 250 ${ }^{\circ} \mathrm{C}$. The MS was tuned every week with perfluorotributylamine as a lock mass and daily checks and blank samples were performed to ensure the system was under control. Quantification was carried out on the base of stable isotope dilution of the ${ }^{13} \mathrm{C}$-labelled compounds. Masslynx software (Waters, Manchester, UK) was used for targeting and quantification of all the analytes.

\subsection{Validation and Quantification}

To assess the quantification limits and the linearity of the developed method, an internal validation protocol was performed. The statistical treatment relied on an analysis of variance to determine the precision and trueness of the data over four non-consecutive days. For this purpose, two kinds of samples were prepared: calibration samples (CAL), corresponding to standard solutions and quality control samples (QCs), where matrix were spiked with the compounds of interest. Each day, five CAL were prepared in duplicate to establish the response function. A conventional linear regression using the least square method was applied. The linearity was calculated by fitting the back-calculated concentrations of the QCs as a function of the introduced concentrations. Three levels of QC fortified were prepared in two replicates using a blank sample matrix. The precision of the method was determined by computing the relative standard deviations for repeatability $\left(\mathrm{RSD}_{\text {mean }}\right)$ at each concentration of level of the QC samples. Trueness also expressed as a bias and defined as the closeness of agreement between the average value of series of test results and an accepted reference value. The final limit of quantification (LOQ) was determined as the lowest concentration in the QCs to obtain a trueness and precision equal to $100 \pm 20 \%$. Finally, accuracy profiles were constructed by plotting concentration versus calculated bias with two sided $95 \%$ confidence limits. ${ }^{[20]}$

\section{Results and Discussion}

\subsection{Optimization of the GC-MS/MS Screening Method}

As recommended by the European Commission, levels of PCDD/Fs and dlPCBs in food samples have to be identified and quantified by GC-HRMS. 
Table 3. Transitions selected for each homologue group of PCDD/Fs and dl-PCBs in GC-MS/MS method

\begin{tabular}{|c|c|c|c|c|}
\hline Compound & $\begin{array}{l}\text { Molecular } \\
\text { mass }\end{array}$ & Formula & Transition 1 & Transition 2 \\
\hline PCB 81 & 291.99 & $\mathrm{C}_{12} \mathrm{H}_{6} \mathrm{Cl}_{4}$ & $290.0>220.0$ & $292.0>220.0$ \\
\hline PCB 77 & 291.99 & $\mathrm{C}_{12} \mathrm{H}_{6} \mathrm{Cl}_{4}$ & $290.0>220.0$ & $292.0>220.0$ \\
\hline PCB 123 & 326.44 & $\mathrm{C}_{12} \mathrm{H}_{5} \mathrm{Cl}_{5}$ & $324.0>254.0$ & $326.0>256.0$ \\
\hline PCB 118 & 326.44 & $\mathrm{C}_{12} \mathrm{H}_{5} \mathrm{Cl}_{5}$ & $324.0>254.0$ & $326.0>256.0$ \\
\hline PCB 114 & 326.44 & $\mathrm{C}_{12} \mathrm{H}_{5} \mathrm{Cl}_{5}$ & $324.0>254.0$ & $326.0>256.0$ \\
\hline PCB 105 & 326.44 & $\mathrm{C}_{12} \mathrm{H}_{5} \mathrm{Cl}_{5}$ & $324.0>254.0$ & $326.0>256.0$ \\
\hline DF083 & 305.98 & $\mathrm{C}_{12} \mathrm{H}_{4} \mathrm{OCl}_{4}$ & $305.9>242.9$ & $303.9>240.9$ \\
\hline DD048 & 321.97 & $\mathrm{C}_{12} \mathrm{H}_{4} \mathrm{O}_{2} \mathrm{Cl}_{4}$ & $319.9>256.9$ & $321.9>258.9$ \\
\hline PCB 126 & 326.44 & $\mathrm{C}_{12} \mathrm{H}_{5} \mathrm{Cl}_{5}$ & $324.0>254.0$ & $326.0>256.0$ \\
\hline PCB 167 & 360.88 & $\mathrm{C}_{12} \mathrm{H}_{4} \mathrm{Cl}_{6}$ & $360.0>290.0$ & $358.0>288.0$ \\
\hline PCB 156 & 360.88 & $\mathrm{C}_{12} \mathrm{H}_{4} \mathrm{Cl}_{6}$ & $360.0>290.0$ & $358.0>288.0$ \\
\hline PCB 157 & 360.88 & $\mathrm{C}_{12} \mathrm{H}_{4} \mathrm{Cl}_{6}$ & $360.0>290.0$ & $358.0>288.0$ \\
\hline DF094 & 340.42 & $\mathrm{C}_{12} \mathrm{H}_{3} \mathrm{OCl}_{5}$ & $339.8>276.9$ & $337.9>274.8$ \\
\hline РCB 169 & 360.88 & $\mathrm{C}_{12} \mathrm{H}_{4} \mathrm{Cl}_{6}$ & $360.0>290.0$ & $358.0>288.0$ \\
\hline DF114 & 340.42 & $\mathrm{C}_{12} \mathrm{H}_{3} \mathrm{OCl}_{5}$ & $339.9>276.9$ & $337.9>274.8$ \\
\hline DD054 & 356.42 & $\mathrm{C}_{12} \mathrm{H}_{3} \mathrm{O}_{2} \mathrm{Cl}_{5}$ & $355.9>292.9$ & $353.9>290.9$ \\
\hline PCB 189 & 395.33 & $\mathrm{C}_{12} \mathrm{H}_{3} \mathrm{Cl}_{7}$ & $394.0>324.0$ & $396.0>326.0$ \\
\hline DF118 & 374.86 & $\mathrm{C}_{12} \mathrm{H}_{2} \mathrm{OCl}_{6}$ & $373.8>310.8$ & $375.8>312.8$ \\
\hline DF121 & 374.86 & $\mathrm{C}_{12} \mathrm{H}_{2} \mathrm{OCl}_{6}$ & $373.8>310.8$ & $375.8>312.8$ \\
\hline DD066 & 390.86 & $\mathrm{C}_{12} \mathrm{H}_{2} \mathrm{O}_{2} \mathrm{Cl}_{6}$ & $389.8>326.8$ & $391.8>328.8$ \\
\hline DD067 & 390.86 & $\mathrm{C}_{12} \mathrm{H}_{2} \mathrm{O}_{2} \mathrm{Cl}_{6}$ & $389.8>326.8$ & $391.8>328.8$ \\
\hline DF130 & 374.86 & $\mathrm{C}_{12} \mathrm{H}_{2} \mathrm{OCl}_{6}$ & $373.8>310.8$ & $375.8>312.8$ \\
\hline DD070 & 390.86 & $\mathrm{C}_{12} \mathrm{H}_{2} \mathrm{O}_{2} \mathrm{Cl}_{6}$ & $389.8>326.8$ & $391.8>328.8$ \\
\hline DF124 & 374.86 & $\mathrm{C}_{12} \mathrm{H}_{2} \mathrm{OCl}_{6}$ & $373.8>310.8$ & $375.8>312.8$ \\
\hline DF131 & 409.31 & $\mathrm{C}_{12} \mathrm{HOCl}_{7}$ & $407.8>344.8$ & $409.8>346.8$ \\
\hline DD073 & 425.31 & $\mathrm{C}_{12} \mathrm{HO}_{2} \mathrm{Cl}_{7}$ & $423.8>360.8$ & $425.8>362.8$ \\
\hline DF134 & 409.31 & $\mathrm{C}_{12} \mathrm{HOCl}_{7}$ & $407.8>344.8$ & $409.8>346.8$ \\
\hline DD075 & 459.75 & $\mathrm{C}_{12} \mathrm{O}_{2} \mathrm{Cl}_{8}$ & $459.7>396.7$ & $457.7>394.7$ \\
\hline DF135 & 443.76 & $\mathrm{C}_{12} \mathrm{OCl}_{8}$ & $443.7>380.7$ & $441.7>378.7$ \\
\hline
\end{tabular}

Nevertheless, a screening method can be used to monitor these contaminants in foodstuffs. Such screening procedures can be based on bioanalytical methods or by GC-MS approach and can be useful to avoid false compliant results. Significant levels of PCDD/Fs and dl-PCBs could then be confirmed by a second method. ${ }^{[21]}$ For economic and convenience reasons, a screening method based on a GC-MS/MS approach was chosen by the Official Food Control Authority of Geneva in order to perform various surveys on food samples.

A classic and simple liquid-liquid extraction was selected among routinely applied rapid sample processing and automation extraction techniques, like pressurized liquid extraction (PLE), microwaveassisted extraction (MAE), supercritical fluid extraction (SFE) or soxhlet-based extraction. Then, as described in US EPA ventional split/splitless injection. ${ }^{[22]}$ Three different injection modes are available for PTV-LV: at-once, either under speed control or using multiple injections. [23] The PTV inlet is a highly flexible GC inlet and is able to perform 'standard' injection modes: split, splitless and flexible temperature and pressure control. A splitless injection of sample volume of $20 \mu \mathrm{L}$ using speed control was selected to obtain a concentration factor of 500. The optimization of the PTV parameters was undertaken following the software procedure which involved a lot of experimental variables as initial and final inlet temperatures, temperature ramp rate, vent pressure/flow/end time and injection speed. Several liners were compared by injecting standard analytes (data not shown) and PTV liner multi baffle deactivated was finally selected due to its ability to obtain higher recoveries and repeatabilities.

Full scan MS spectra of native PCDD/ Fs and dl-PCBs were performed to choose the most sensitive ion transitions for each compound. The use of multiple reaction monitoring (MRM) allowed the production of selected daughter ions for chromatographically coeluting native and labelled compounds to be monitored. The isolation of molecular ions from the produced ions had to be optimized for each congener, and specific isolation parameters were applied for each of them. The behavior of PCDD/ Fs in MS/MS was characterized by the loss of $\mathrm{COCl}, 2 \mathrm{COCl}, \mathrm{COCl}_{3}, \mathrm{COCl}_{2}$ and $\mathrm{Cl}$ from the molecular ions, but the most abundant ion was $[\mathrm{M}-\mathrm{COCl}]^{+}(-\mathrm{m} / \mathrm{z} 63)$. The $\left[\mathrm{M}-{ }^{35} \mathrm{Cl}^{35} \mathrm{Cl}\right]^{+}(-\mathrm{m} / \mathrm{z} 70)$ and $\left[\mathrm{M}-{ }^{35} \mathrm{Cl}^{37} \mathrm{Cl}\right]^{+}$ $(-\mathrm{m} / \mathrm{z} 72)$ product ions were monitored for quantitative purposes. Chromatograms of a standard solution and of an extract of egg yolk are shown in Fig. 1.

\subsection{Method Validation and Quantification}

Validation was carried out on the 29 PCDD/Fs and dl-PCBs using a specific internal deuterated standard for each compound. Prior to any analysis, a sample of each matrix (animal fat or egg yolk) used for QC preparation was tested to evaluate the interfering contaminants. Three levels of independent QC samples covering the entire validation range were prepared on four non-consecutive days in duplicate. Five calibration samples were prepared in hexane in duplicate. Linearity was calculated by fitting the back-calculated concentrations of the QCs as a function of the introduced concentrations. With coefficient of determination above 0.9983 , assays were found to be linear for each analyte over the entire concentration range tested. Trueness, representing systematic errors, was expressed as the relative bias and generally varied between +51 and $-19 \%$ 


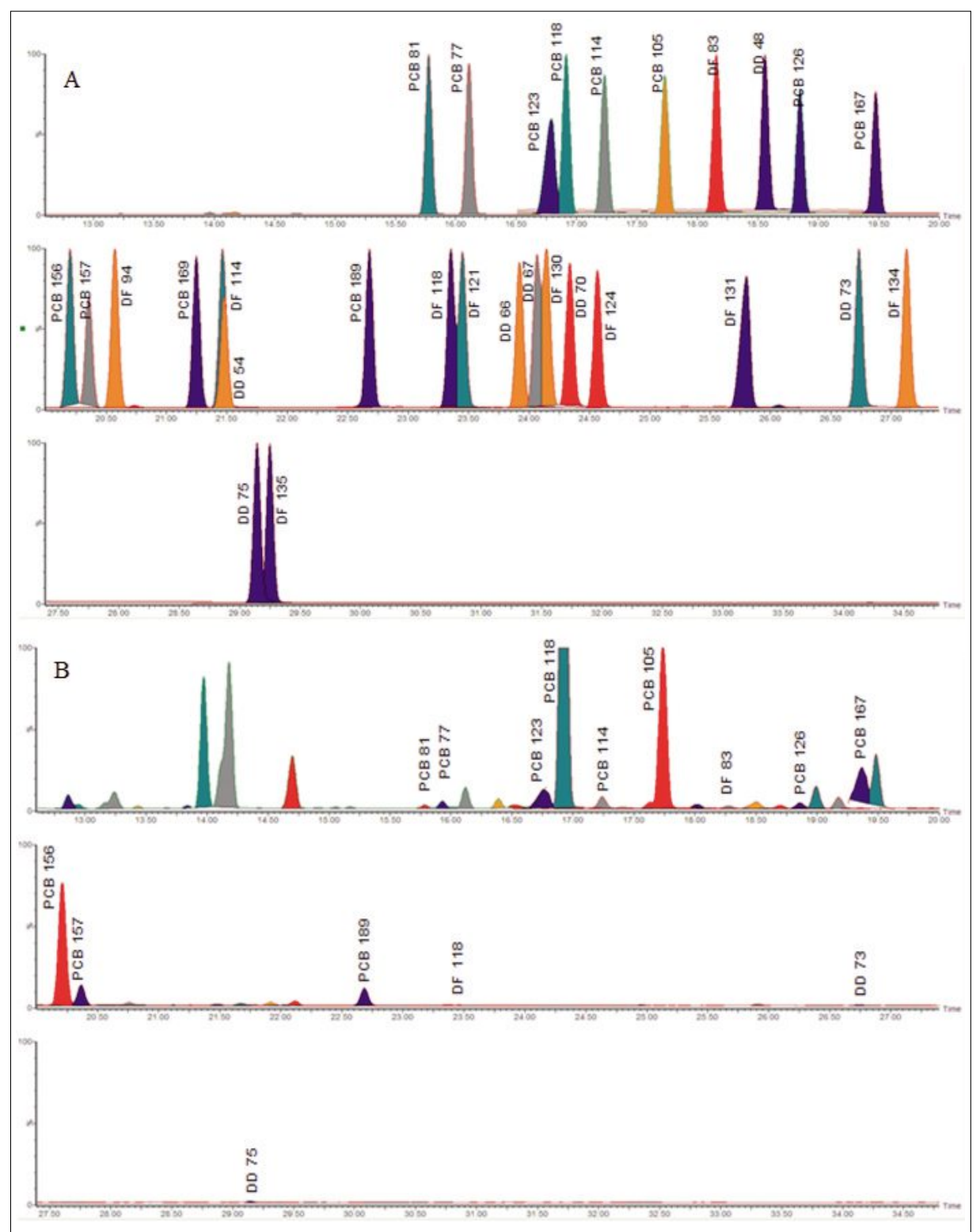

Fig. 1. GC-MS/MS chromatograms of (A) standard solution (dl-PCBs: $10 \mu \mathrm{g} / \mathrm{L}, \mathrm{TeCCD} / \mathrm{Fs}: 8 \mu \mathrm{g} / \mathrm{L}$, $\mathrm{Pe}-\mathrm{Hx}-\mathrm{HpCDD} / \mathrm{Fs}: 20 \mu \mathrm{g} / \mathrm{L}$, OCDD/Fs: $40 \mu \mathrm{g} / \mathrm{L}$ and (B) extract of egg yolk.

and $\mathrm{RSD}_{\text {mean }}$ between 8 and $24 \%$. For food analysis, the limit of quantification was set between $4 \times 10^{-6}$ and $0.04 \mathrm{pg} / \mathrm{g}$ for dl-PCBs and between 0.004 and $1 \mathrm{pg} / \mathrm{g}$ for PCDD/ Fs (Table 4).

Levels of PCDD/Fs and dl-PCBs found in 14 positive samples were confirmed by GC-HRMS reference method and showed a good correlation with GC-MS/MS (Fig. 2 ). These analyses were performed by the Official Food Control Authority of Bern and revealed total TEQ values lower than that obtained by our GC-MS/MS method except for one sample. In the lower concentrations range, significantly higher bias was observed between the two measurements. This difference could be explained by the contribution of PCB 156 which was the major compound in these animal fats. In seven samples, the concentrations of this congener measured by GC-MS/ MS were significantly lower than by GC-
HRMS. This comparison of the two procedures revealed false positives provided by the screening method but no false compliant (false negative) were declared after confirmation by GC-HRMS. These results confirmed EU Commission Regulation $252 / 2012$ that specifies that $2-10 \%$ of negative samples must be analyzed by a confirmatory method for false negative rate assessment. In comparison to the bioassay approach, a worst case scenario, symbolized by contamination patterns involving exclusive contribution of non-monitored congeners to the TEQ, could occur. But the lower estimation of total value TEQ giving false negative is less important for the GCMS/MS method, because each congener was individually quantified.

\subsection{Survey of Animal Products in the Geneva Area}

Research focused on the evaluation of the contamination of foodstuffs produced in Les Cheneviers area. The concentration in dioxins in 11 samples of meat and eggs were close to the official limits for these matrices but no restriction was justified. [24] The Official Food Control Authority of Geneva began an investigation in response to the finding of high concentrations of dioxins in soil based on these public studies. This survey aimed to investigate the current levels of dioxins found in food in Geneva. Individual samples of animal fats and yolk eggs were collected in 2009.

Due to the large volume of data produced during the validation process, only summarized results are presented here. All data are reported as lower-bond, meaning that when congeners were not detected, they assumed to be not present at the level of the detection limits.

A sampling plan was established by collecting samples of beef, sheep and pork from animals farmed in defined circular areas in Geneva up to $25 \mathrm{~km}$ away from the garbage incinerator Les Cheneviers. These samples represented the dispersion among the 121 animal products for a total of approximately 2'800 beef samples, 2'000 pork and 11'000 fowl.

The total represented 121 samples which were distributed among the species:

- 83 beef samples from 32 producers

- 16 lamb or mutton samples from 10 producers

- 8 pork samples from 6 producers

- 14 batches of 6 eggs from 14 producers

The results were expressed in pg WHO-TEQ/g fat and Table 5 shows the distribution of the contaminants in the five zones around the incinerator. No increase of concentration of dioxins was detected in the surroundings of Les Cheneviers and no correlation has been established between the proximity of the incinerator and the levels of contamination. Consequently, the animal products produced in Geneva area did not represent a risk for human health. The results evidenced a good agreement with data from a Swiss survey performed in 2008. [25]

Two bovine animals, a pig, and a batch of eggs, showed concentrations higher than the legal values established by the Europe legislation. dl-PCBs contributed at $95-100 \%$ to total TEQ values for the non-compliant bovine fats. Supplementary samples were collected on farms in the location of the contaminated beef and all tested samples were lower than the regulation limits. The two non-compliant samples were considered to be isolated cases and no further investigation was conducted at the production sites.

The contaminated pork did not come from a farm, but was submitted from a local owner and was not destined to join 
Table 4. Validation data of PCDD/Fs and dl-PCBs in GC-MS/MS method

\begin{tabular}{|c|c|c|c|}
\hline Compound & $\begin{array}{c}\text { LOQ } \\
{[\mathrm{pg} / \mathrm{g}]}\end{array}$ & $\begin{array}{c}\text { Recovery } \\
{[\%]}\end{array}$ & $\begin{array}{c}\text { RSD }_{\text {mean }} \\
{[\%]}\end{array}$ \\
\hline PCB 77 & 0.00002 & 140 & 17 \\
\hline PCB 81 & 0.00002 & 145 & 17 \\
\hline PCB 105 & 0.00004 & 126 & 12 \\
\hline PCB 114 & 0.0002 & 129 & 13 \\
\hline PCB 118 & 0.00002 & 116 & 12 \\
\hline PCB 123 & 0.00002 & 106 & 17 \\
\hline PCB 126 & 0.04 & 127 & 8 \\
\hline PCB 156 & 0.0002 & 81 & 20 \\
\hline PCB 157 & 0.0002 & 111 & 19 \\
\hline PCB 167 & 0.000004 & 101 & 20 \\
\hline PCB 189 & 0.00004 & 125 & 19 \\
\hline DD048 & 0.4 & 151 & 20 \\
\hline DD054 & 1 & 138 & 14 \\
\hline DD066 & 0.2 & 126 & 21 \\
\hline DD067 & 0.2 & 127 & 17 \\
\hline DD070 & 0.2 & 127 & 17 \\
\hline DD073 & 0.04 & 145 & 19 \\
\hline DD075 & 0.004 & 135 & 17 \\
\hline DF083 & 0.04 & 141 & 17 \\
\hline DF094 & 0.02 & 129 & 16 \\
\hline DF114 & 0.20 & 120 & 24 \\
\hline DF118 & 0.2 & 127 & 12 \\
\hline DF121 & 0.2 & 127 & 15 \\
\hline DF124 & 0.4 & 121 & 13 \\
\hline DF130 & 0.2 & 108 & 21 \\
\hline DF131 & 0.04 & 132 & 14 \\
\hline DF134 & 0.1 & 116 & 21 \\
\hline DF135 & 0.004 & 130 & 15 \\
\hline
\end{tabular}

the food production chain. The total TEQ value was 8 -fold higher than the regulation limit. The main contribution was $94 \%$ from PCDD/Fs to total TEQ values. As for the non-compliant pork, the set of eggs was from private production not destined to be commercialized. It revealed a high total TEQ value including a contribution of $29 \%$ PCDD/Fs.

A second sample was analyzed and confirmed the preliminary results. The Official Food Control Authority of Geneva was asked to identify the origin of the PCDD/Fs and dl-PCBs and conclude that contamination originated from the ashes that were spread on the nest. Sanitation works were promptly undertaken to resolve the contamination.

These values have to be carefully analyzed because a high variability was observed in the analytical results. In fact, the environment of each animal could be extremely different and provide dispersive contamination in a batch of samples for a foodstuff group. Sampling locations of the animals reflect spatial distribution of the species in comparison of the levels of industrial activity in their living areas. ${ }^{[26]}$ A detailed investigation on concentrations of dioxins in milk reported notable fluctuation over time.[27] These fluctuations may be explained by changes in the contaminant concentrations of dietary inputs, grass and silage, consumed by the cattle. Moreover, the results were almost one order of magnitude below the maximum allowed levels and could be explained by the use of the lower-bond concept.

\section{Conclusions}

A method allowing the screening of PCDD/Fs, dl-PCBs and total-TEQ values in various foodstuffs was developed and validated in various foodstuffs. Even if bias were observed for the congener PCB 156 , the results showed a good agreement between GC-MS/MS and GC-HRMS. Compared to bioassay approaches, this GC-MS/MS based screening method allows for individual quantification of each congener analyzed in foodstuffs. Regarding European analytic criteria re-

Table 5. Concentration of selected PCDD/Fs and dl-PCBs in pg/g WHO98-TEQ in animal fats around the incinerator Les Cheneviers

\begin{tabular}{|c|c|c|c|c|c|c|c|c|c|c|c|c|}
\hline & $\mathrm{N}$ & 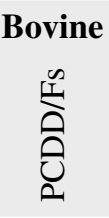 & 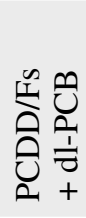 & $\mathrm{N}$ & 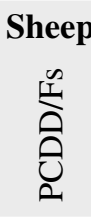 & 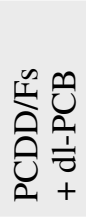 & $\mathrm{N}$ & 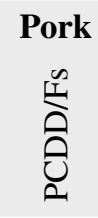 & 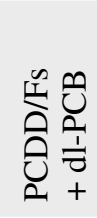 & $\mathrm{N}$ & 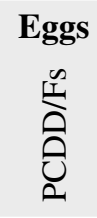 & 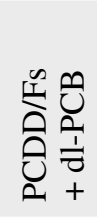 \\
\hline$<2 \mathrm{~km}$ & 3 & 0.00 & 1.04 & 0 & - & - & 1 & 0.02 & 0.20 & $1 *$ & $0.25^{*}$ & $2.19 *$ \\
\hline $2-5 \mathrm{~km}$ & 11 & 0.07 & 1.59 & 2 & 0.00 & 2.25 & $3 *$ & $0.00 *$ & $0.04 *$ & 3 & 0.00 & 1.32 \\
\hline 5-10 km & 23 & 0.03 & 1.56 & 7 & 0.00 & 1.59 & 1 & 0.00 & 0.04 & 4 & 0.09 & 1.75 \\
\hline 10-15 km & 13 & 0.01 & 2.22 & 3 & 0.00 & 0.45 & 0 & - & - & 5 & 0.25 & 1.57 \\
\hline 15-25 km & 33 & 0.10 & 2.26 & 4 & 0.00 & 0.31 & 2 & 0.17 & 0.91 & 0 & - & - \\
\hline mean & 83 & 0.04 & 1.95 & 16 & 0.00 & 1.14 & $7 *$ & $0.05^{*}$ & $0.31 *$ & $13^{*}$ & $0.14^{*}$ & $1.62 *$ \\
\hline mean $\mathrm{CH}$ & 38 & 0.59 & 2.77 & & & - & 15 & 0.17 & 0.35 & 43 & 0.62 & 1.07 \\
\hline
\end{tabular}

(*)only samples destined for food production 


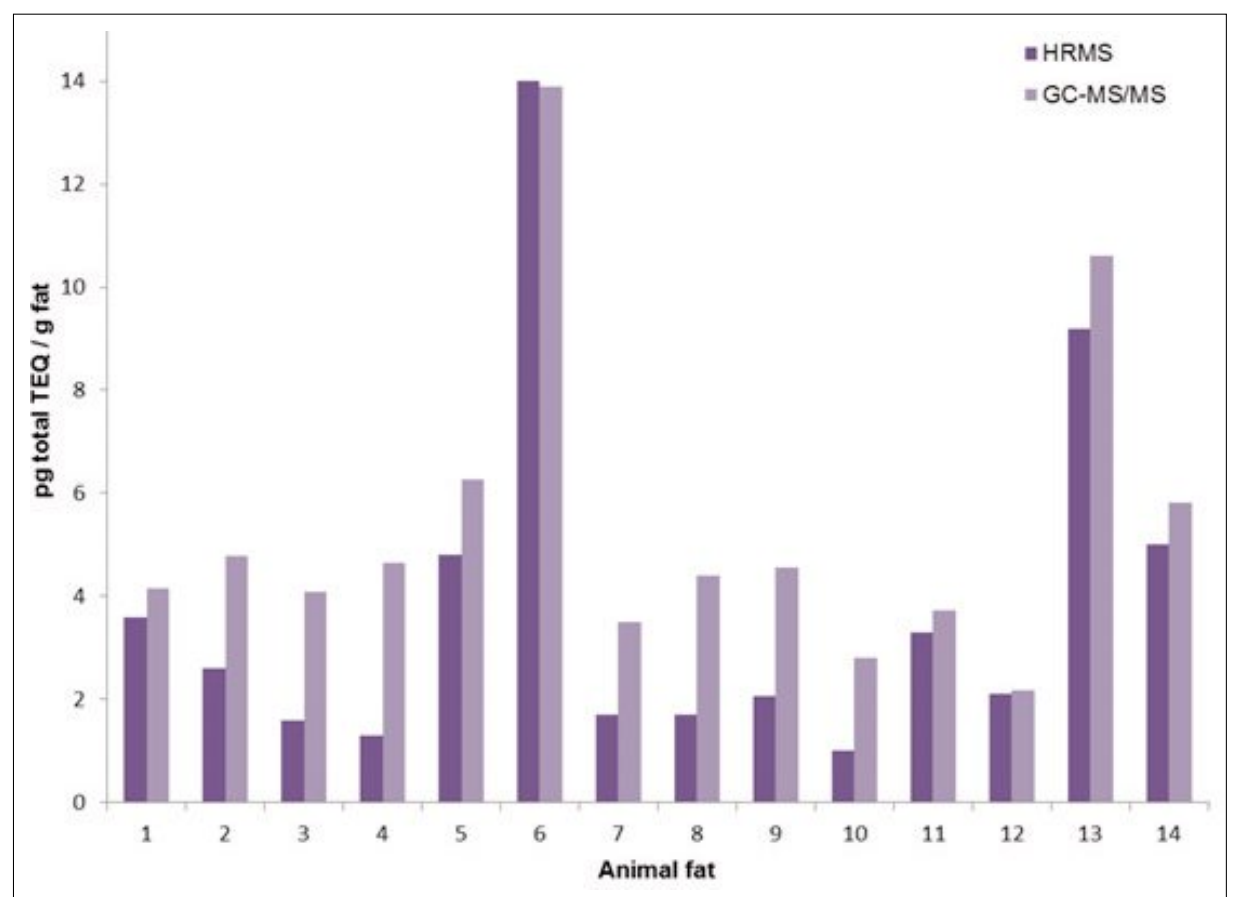

Fig. 2. Comparison of total TEQ values between HRMS and GC-MS/MS methods.

quested for screening methods, the results were relevant for routine control plans and meet European directive which required less than $5 \%$ of false negatives. The method is now routinely in use for various foodstuffs screening program designed by the Official Food and Veterinary Control Authority of Geneva.

Received: September 10, 2014

[1] A. Tard, S. Gallotti, J.-C. Leblanc, J.-L. Volatier, Food Addit. Contam. 2007, 24, 1007.

[2] J.-F. Focant, C. Pirard, G. Eppe, E. De Pauw, J. Chromatogr. A 2005, 1067, 265.

[3] E. Eljarrat, D. Barcelo, J. Mass Spectrom. 2002, 37,1105 .

[4] Bundesamt für Umwelt, Wald und Landschaft, 'Dioxine und Furane, Standortbestimmung', 1997, www.bafu.admin.ch

[5] J.-F. Focant, C. Pirard, E. De Pauw, Talanta 2006, 63, 1101.
[13] M. Usel, R. Muggli, 'L'incidence des cancers à proximité de l'usine d'incinération des ordures des Cheneviers', Faculté de médecine de l'Université de Genève, 2008, www.ge.ch

[14] J.-F. Focant, G. Eppe, C. Pirard, E. De Pauw, J. Chromatogr. A 2001, 925, 207.

[15] U.S. Environmental Protection Agency EPA, Method 1668. Method 1668B, 'Chlorinated Biphenyl Congeners in Water, Soil, Sediment, Biosolids, and Tissue by HRGC/HRMS', Washington DC, 2008.

[16] E. Reiner, R. Clement, A. Okey, C. Marvin, Anal. Bioanal. Chem. 2006, 386, 791 .

[17] K. Warrall, A. Newton, R. Rao, D. Wood, Application Note, Waters, 2003.

[18] G. Eppe, J.-F. Focant, C. Pirard, E. De Pauw, Talanta 2004, 63, 1135.

[19] US Environmental Protection Agency EPA, Method 1613, 'Tetra- through octachlorinated dioxins and furans by isotopic dilution HRGCHRMS', Washington DC, 1994.

[20] A. Bugey, Y. Janin, P. Edder, S. Bieri, Anal. Bioanal. Chem. 2013, 405, 4177.

[21] 'Commission regulation of 21 March 2012, laying down methods of sampling and analysis for the official control of levels of dioxins, dioxin- like PCBs and non-dioxin-like PCBs in certain foodstuffs and repealing Regulation (EC) No 1883/2006, 252/2012/EC', Off. J. Eur. Commun. 2012, L 84/1.

[22] F. A. Esteve-Turrillas, E. Caupos, I. Llorca, A. Pastor, M. De La Guardia, J. Agric Food Chem. 2008, 56, 1797.

[23] W. Engewald, J. Teske, J. Efer, J. Chromatogr. A 1999, 842, 143

[6] Communiqué de presse du département du territoire et du département de l'économie et de la santé, 'Usine des Cheneviers: des émissions de polluants sous contrôle', 2009.

[7] Office fédérale de la santé OFSP, Ordonnance du DFI sur les substances étrangères et les composants (OSEC), 817.021.23, chapitre 7, 2014.

[8] Office fédérale de l'environnement OFEV, 'Polychlorobiphényles (PCB) dans les eaux en Suisse', 2010, www.bafu.admin.ch

[9] European Food Safety Authority, 'Results of the monitoring of dioxin levels in food and feed', EFSA J. 2010, 8, 1385.

[10] 'Commission regulation of 19 December 2006 - setting maximum levels for certain contaminants in foodstuffs', 1881/2006/EC, Off. J. Eur. Commun. 2006, L364/24.

[11] Secrétariat du Grand Conseil Genevois, 'Pour une usine des Cheneviers propre et une information transparente', 2009, www.geneve. ch

[12] Ordonnance sur les atteintes portées aux sols (OSol), 814.12, 2008, p.10.

[24] P. Edder, 'Evaluation des denrées alimentaires produites à proximité des Cheneviers, Service de la Consommation et des Affaires Vétérinaires', 2009, www.avuc.ch

[25] Bundesamt für Gesundheit BAG, 'Dioxine und PCB in Schweizer Lebensmitteln', 2008, $w w w$. blv.admin.ch

[26] A. Fernandes, P. Dicks, D. Mortimer, M. Gem, F. Smith, M. Driffield, S. White, M. Rose, Mol. Nutr. Food Res. 2008, 52, 238.

[27] I. R. Lake, C. D. Foxall, A. Fernandes, M. Lewis, M. Rose, O. White, A. Dowding, Chemosphere 2013, 90, 72 . 